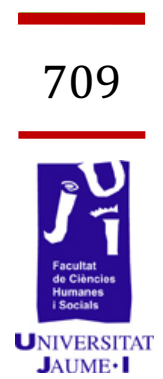

\title{
The Phonological Evolution of Current Spoken English: A Case Study
}

Andrea Esteve Recatalà al188050@uji.es 
The present project aims at examining the innovative phonological features of current spoken English. In order to accomplish this intricate task, several sections are introduced to make explicit the ongoing phonological tendencies. A case study was conducted to provide a detailed explanation of the new trends, their users as well as people's attitudes towards them. Once an exhaustive exploration of these aspects was completed, this research deepened on the issue of whether the stated contemporary phonological trends could be part of a new RP. As a support of this hypothesis, several phoneticians as well as linguists provided their own account on this topic. It seemed apparent that the selected topic is one of the concerns of many authors these days. They are concerned with Estuary English and Received Pronunciation since they came to be seen in opposition. However, they could alternatively be seen as a modern variety of RP.

Key Words: Standard English, Received Pronunciation, Ongoing Phonological Features, RP Change

\section{Introduction}

The current research seeks to exhibit the most outstanding changes in current spoken English. Hence, this manuscript will be tackling several sections. Firstly, the clarification of the chief objectives that triggered me to explore this field of study arises as a crucial starting point. Apart from providing a detailed description of them, secondly, a detailed account of the materials needed for the case study as well as the methodology followed will be fully explained. It is extremely apparent that English is a language that has been involved in constant evolution throughout the ages. Therefore, it is highly required to analyse deeply whose speech is evolving. That is, thirdly, who the participants of this study and what the ongoing present-day phonological tendencies might be should be settled. Thus, the entire analysis embraces significant information such as new phonological tendencies, their users as well as social reaction to those changes can be observed. Fourthly, the project additionally discusses the hypothetical case in which the previously explored new features are part of the "Received Pronunciation". Several old features penetrating "Received Pronunciation" could be the support of the contemplated hypothesis. Once the whole arguments have been exposed, it is conceivable to draw some conclusions. "Discussion" section embraces those final remarks. Eventually, it is significant to mention that additional annexes could not be included due to length limits. Nevertheless, they have been pivotal material in my research. 
III. Objectives

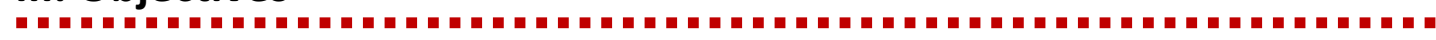

The topic of the present project was firstly introduced to the author of this paper in one of the subjects in her stay in the University of Southampton. The main concern of this course was to examine and explore the current spoken English features. Special attention should be paid to the fact that the student was allowed to contrast and compare those features in every-day life speech. Covering these characteristics of current spoken English in England was a unique opportunity that favoured the student to cope with the final project. As a consequence, the student could be exposed to those features and acquire a highly required background knowledge. Before deepening on the explanation of the pilot study itself, it is highly required to clarify why the word "phonological" has been used to regard the new spoken tendencies. It is exclusively a matter of explaining the terminology employed. On the one hand, one reason why "phonological" is a term that has been used to define the innovative tendencies is because they were referred to "phonological" in the University of Southampton's module. On the other hand, although English native speakers do not take notice of these tendencies being new phonemes, linguists might refer to these innovative tendencies as phonological. Therefore, the term "phonological" has been used in the project taking into account this explanation.

\section{Methodology}

Being entirely involved in an English environment and exposure was crucial in the development of the present project. As a result of being in contact with several native speakers, the student could contrast the features covered in the aforesaid module. Moreover, the methodology which has been followed in the project runs as follows.

Once the student listed the whole range of features that she was willing to detect, she decided which method she could follow to obtain the accurate data. After some prior deliberation, two techniques were the ones employed to gather the proper corpus of data for the final project.

On the one hand, the student asked several English native speakers whether they could record themselves when having a conversation. She would have told the native speaker the topic in advance. It needs to be highlighted that the student knew which topic would be the most suitable one for each native speaker. This previous knowledge was strongly determined by the student's experience and contact with the participant. She was aware of the fact that she could detect several innovative features in his or her speech. Moreover, she watched numberless videos of famous bloggers, and interviews to famous singers, whose speech meets the current spoken English features involved in this final project. As a consequence of detecting these characteristics, the student downloaded the suitable material, chopped it, and analysed it very meticulously. 
On the other hand, the second technique used to conduct the recordings was the succeeding one. Each participant was required to pronounce a distinct set of words. In this word groups, some of the current spoken English features could occur. It needs to be claimed that the recording of these groups of words can be found in Annex I. In addition to that, the phonemic transcription of these words is additionally presented in Annex II. These words are, firstly, phonemically transcribed in RP English. Secondly, they are transcribed taking into account the innovative features of current spoken English.

Eventually, as the final step of the process of analysing the obtained data, the student listened to the recordings countless times. In addition to that, she classified them into "characteristics" so that they could be wellorganised in the attached disk. She reckoned it was a suitable suggestion for the members of the board not to be mislaid. Moreover, for the recordings to be as accurate as possible, the student adopted a method in which she chopped the "irrelevant" audio information.

\subsection{Participants}

As stated in the previous section, the people who participated in the student's final project are English native speakers. The entire number of cooperators can be considered confidant as well as advisors of the student throughout the whole project. They are aged between nineteen and twenty nine. However, the student's research has encountered several instances in video recordings on the Internet where older generations have also acquired these new phonological tendencies. It needs to be acknowledged that the task's realisation could not be accomplished without their assistance.

Taking into account their place of provenance, it can be asserted that they are mostly from the Southeast of England. Particularly, they come from cities such as Southampton, Portsmouth, Bath, London, Epsom (Surrey), and Horsham. Some critics considered these new phonological tendencies to be highly associated with Southeast of England. However, some other analysts asserted that these innovative phonological trends were occurring in all regions of the United Kingdom. In fact, the University of Southampton's lecturer, who was in charge of teaching the module, regarded these characteristics to be generalised in the whole country. Based on this controversy, the student did not merely recorded people from the Southeast of England. Additionally, bearing this contention in mind, she recorded people from the Liverpool, Manchester, and Nottingham. 


\subsection{New phonological tendencies}

Under the "new phonological tendencies" heading, the previously mentioned new trends regarding traits of current spoken English are introduced. These features are presented in distinct sections so that the reader cannot be mislaid. It is remarkably significant to explain how the information is exhibited within each subsection. Firstly, the feature is named as well as fully defined. Secondly, the number of the corresponding recording to each new feature can be found afterwards. Although the recording can be listened to in the disk attached, the number serves to encounter the track in which the word or sentence is placed. Thirdly, some evidence of each phonological trait needs to be provided. As the topic that is being analysed is contemporary and daily focused, instances on social networks are given. It is apparent that social networks and media are pivotal when showing new trends as well as changes. Therefore, following the trait explanation and the track's number in the recording, several examples on social media are displayed.

\subsubsection{Ambiguity between $\langle t h\rangle, / \vartheta /$ and $/ f /, / v /$.}

Generalised loss of the differentiation between $<\mathrm{th}>, / \theta /$ and $/ f /, / v /$. This new trend consists of the replacement of the two "th" sounds by "f" or " $v$ ". Thus, words such as brother, thing, think, together, another, bath, other, with, idea, thousand, anything, everything, something are pronounced like / brıvə/, / fin /, / fink /,/ tə'gevə/, / ə'n^və/, /ba:f/, /'^və/, wiv/, /ai'fıə/, /'fazzənd, / 'enıfın/, / 'evrıfın/, and /'sımfin/. Morever, it needs to be emphasised that 'This feature is only sporadic in Cardiff, Liverpool, and Edimburgh'. (Kerswill 2000)

Evidence of this particular English phonological tendency can be listened to in the attached disk from track 1 to track 24. Moreover, as stated above, social networks might be considered as reflections of everyday life speech. Therefore, those changes can be contrasted in the people's typewriting. That is, the ambiguity between $\langle\mathrm{th}\rangle, / \theta /$ and $/ \mathrm{f} / \mathrm{/} / \mathrm{v} / \mathrm{can}$ also be observed in the social networks. Investigating on social networks can be revealing when analysing any current spoken language. Evidence of this particular trait can be seen in some people's tweets. It is imperative mentioning that the author of this project did not wish to reveal these people's identity. Therefore, she covered their names as well as their profile pictures.

\subsubsection{Vocalisation of the dark "l"}

In the most part of English dialects, the /I/ sound involves two allophones. On the one hand, the first allophone is the dark or clear /I/. It 'involves contact between the tip of the tongue and the alveolar ridge, but instead of the air being blocked at the sides of the tongue, it is also allowed to pass down the sides' (Johnson \& Britain 2007). On the other hand, the second allophone is commonly regarded as velarized /// which requires a distinct articulation. In order to utter this particular /I/ 'the retraction of 
the back of the tongue towards the velum' (Johnson \& Britain 2007) is needed.

The widespread phenomenon of I-vocalisation is described as the vocalisation of dark / $/$ in syllable rhymes' (Johnson \& Britain 2007). In other words, it is conceivable to observe an addition of short / $\mathrm{u} /$ in front of post-vocalic -l.

In addition to that, it is noteworthy to present the particular phoneme which is used to identify this peculiar phenomenon. ([1]) is the commonly
agreed phoneme to refer to the velarised /I/. Thus, words like "table", which used to be represented as /'teibl/, would be velarised and illustrated as [te:bf]).

Despite the fact that using " ([1]) " to represent the velarised / $/$ is the accurate system, it is conceivable to observe the present phenomenon illustrated as follows. For instance, words such as feel, cool, milk, built people, possible, label can be symbolised as [fi:w], [ku:w], [mi:wk], [biwt], [pi:pu], [ppsəbou], [leibu] (Johnson \& Britain 2007). Furthermore, it is of remarkable significance to declare that, although this new tendency is exceptionally outstanding in current spoken English in Britain, 'it appears to be in other dialects including American English, New Zealand English, and Falkland Island English' (Johnson \& Britain 2007).

Dealing with the audio evidence, several tracks exemplify the selected phenomenon. They range from track 24 to track 45 . Connected with the audio files, Annex II embraces the entire number of transcriptions in RP and in current spoken English. Moreover, evidence on social networks, particularly Twitter, reveals the succeeding material.

\subsubsection{Recurrent presence of glottal stop}

The commonly named "glottal stop" has been additionally regarded as "T-Glottalisation" phenomenon. The figure of the recognised phonetician John Christopher Wells can be studied as one of the linguists who defined the present notion. According to him, the glottal stop is a plosive which has been created by the closure and the opening of the glottis afterwards.

It is worth mentioning the manner in which the glottal stop is highly distinguished. In other words, the way in which it is symbolised needs to be exhibited. A glottal stop is expressed by the succeeding symbol: ?. Furthermore, a glottal stop is mostly employed as a " $t$ " sound to some extent. However, this particular usage cannot be considered the exclusive one. In fact, this phenomenon embraces several additional functions.

Firstly, in certain positions, the glottal stop can be regarded as an allophone of the phoneme. The best example which illustrates this first glottal stop function is the word "pointless" / poin ? lis/. Secondly, the glottal stop is exclusively adopted as an allophone of " $\mathrm{t}$ " at the end of a word, and if the preceding sound is a vowel. Instances of this function are words such as the following ones: football /'fopbo:l/, outside /'avt'sard/, button / 'b^tn/, Gatwick / gæ, ?wIk/ , fitness /'fI Pnəs, not only this but also

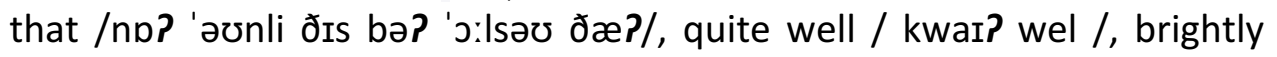


/'brasPli/, that name / ठə? 'nerm/ utmost, /'^Pməust/. Thirdly, adding emphasis is another function that the glottal stop comprises. This emphasis is placed on the syllable that begins with a vowel sound. In $\mathrm{BrE}$, this emphasis helps the task of avoiding the " $r$ " sound. An example that clearly illustrates this purpose is the word "underexpose" / ^ndə ? Ik'spəひz /. Fourthly, it should be highlighted that the T-glottalisation phenomenon is occasionally adopted to strengthen either " $\mathrm{t}$ " or " $\mathrm{tr}$ " at the end of a syllable. Additionally, it can also be applied to empower the succeeding sounds " $p$ ", " $t$ ", and " $k$ " when followed by a consonant or at the end of a word. In this particular case, the glottal stop's nomenclature is slightly modified. The glottal stop phenomenon when having the previous behaviour can be named as "glottal reinforcement". For instance, words such as "teaching" /'ti:Ptfin/, "April" '/er Pprəl/ as well as "right" /rai?t/ reinforce this distinguishing wonder. Fifthly, after contrasting information in academic articles and in books, the location where the "glottal stop" should be placed can be asserted. It has been agreed by several authors that the "glottal stop" should be placed: before a consonant, before a vowel, before a pause, as well as in the middle of a words between vowels.

\subsubsection{Happy Tensing}

Happy Tensing can be contemplated as one of the phonological features that is being progressively adopted by modern dialects. Trudgill et al (2000) distinguished between ongoing changes and a propensity for change. When asserting this statement, they remarked the term "Happy Tensing" as one of the new tendencies taking place nowadays. Therefore, it is imperative to define what is termed "Happy Tensing". As Wells (1982) asserted, "happy tensing" is the use of a non-centralised [i:] in final, unstressed position'. That is, this phenomenon occurs in words whose last vowel is originally /I/. Hence, what "happy tensing" does is to replace this /I/ sound by a long /i:/. It is exemplified in words such as "coffee" / 'kpfi:/, "city" / 'stti:/, "pity" / 'prti:/, "picky" / 'prki:/, "everybody" / 'evri, bodi:/, among others. In addition to that, it has been agreed that this concept is an exclusively urban feature which generally belong to urban speech.

Special attention should be paid to the degree of occurrence of this phenomenon. Trudgill (2000) provided the succeeding percentages. In 1850s, "Happy Tensing" could not be considered as a phenomenon itself since its occurrence was $0 \%$. A decade later, it suffered a dramatic increase in occurrence embracing $25 \%$. Eventually, in the period of time which ranges from 1870 s and 1889 , the present phenomenon comprised $42 \%$ of its usage. He concluded by asserting that it is apparent that "happy tensing" was also present in New Zealand. Therefore, critics tend to believe that it arrived to New Zealand from Britain. Nevertheless, he contrasted this statement by claiming that this phenomenon 'started life independently in New Zealand' (Trudgill 2000).

\subsubsection{Rising intonation}

Another ongoing phonological tendency that is occurring in current spoken English is the "Rising intonation" phenomenon. It can additionally 
be entitled as "Aussie uplift", "upspeak", or "uptalk". Apart from these denominations, it can be referred to as "HRT" which stands for "High Rising Terminal".

Special mention should be made to the fact that it has become such an every-day life term that it is conceivable to encounter in the dictionary the terms "uptalker" and "uptalking". On the one hand, "uptalker" would refer to the person who "uptalks". On the other hand, the notion "uptalking" is applied to denote the adjectival form of the word. For instance, an "uptalker" would utter the statement "I have bought a new pairs of shoes" as it were an inquiry. In addition to that, it is noteworthy asserting the effect it causes on the hearer. It has been commonly agreed that it could sound unsure, hesitant, as well as tentative. It could also confuse the hearer since he or she could believe that they need to answer what it is not truly a question.

\section{Discussion and conclusion}

Once the new trends regarding ongoing phonological features have been stated, it is a must to provide the people who are associated with them. It has been broadly consented that the users of these new tendencies are a vast number of relatively young people. However, it is also conceivable to encounter older people applying these traits in their speech. Putting aside who the users might be, it can be asserted that it is apparent that people speak using these new features for group identity.

Dealing with the social classes where they regularly belong to, it can be asserted that they appertain to all classes. Despite the fact that these features' users belong to all classes, these innovative phonological tendencies can be constantly found in the speech of the well-known controversial "chavs". The term "chav" can be considered within the British slang. It symbolises a person who wears fashionable brands and flashy jewelry. However, he or she is regarded as having bad or lower-class or taste. According to the Dictionary.com, this term originally emerged in 1995 from the gypsy word "chavo" or "chavi" which possessed the meaning of boy, baby, child, and youth.

Tackling with the results obtained in the case study, it can be asserted that 25 per cent of the recordings' participants were reluctant to adopt these innovations in their speech. They considered them to be vulgar as well as low-class. Notwithstanding that they were aware of the fact that these features are a substantial part of current spoken English, they denied the possibility of recording themselves. The reason they defended was the fact that they were not willing to be involved in this "kind of speech". Quoting from someone's words, it is conceivable to claim the following statements: "I've got a quite posh/ accent and I wouldn't sound right" or "Sorry, I wouldn't normally say that". With these two statements, it is possible to observe some sense of detachment or even refusal, repudiation, and unwillingness. Furthermore, the rest of participants in the project's case study accepted to be involved in the recordings. They were 
reckoned on the basis of $75 \%$. They acknowledged that these innovations were present in their every-day life environment. Some of them argued that they would not regularly use them. However, there were certain situations in which they do not pay attention to their pronunciation, and they do include them in their speech. Furthermore, it can be claimed that a huge number of participants consider these features to be part of their way of speaking. They stated that they no longer consider the possibility of saying "think" as /'Oink/.

As aforesaid, it seems apparent that certain phonological features are encroaching on Received Pronunciation. Instances of it are given by several academic researches, articles, and books. For instance, the article published in 1994 entitled "The Cockneyfication of RP?" suggests a modification of RP towards the previously mentioned Cockney accent. Another article showing surprise to this ongoing tendency is the one entitled "What's happening to Received Pronunciation?". It was published in 1997 in the English Phonetic Society of Japan. Additionally, "Is RP turning into Cockney?" is strongly related with this current concern. It is an article enclosed in "Studies in Communicative Phonetics and Foreign Language Teaching Methodology". Eventually, despite the large amount of articles and research papers where this topic is studied, exclusively another article should be mentioned. It is entitled "Whatever happened to Received Pronunciation?" and it was published in 1997 by University of Jaén.

"There is a common perception in the United Kingdom today that the RP accent is disappearing' (Trudgill 2008). Having this accent is no longer considered a requirement to get a job or to be part of the BBC as it used to be. People tend to disregard the possibility of the previously mentioned innovative phonological features being included in the "new" RP. Notwithstanding, it is a fact that 'RP is subject to change' (Trudgill 2008). In fact, it was Trudgill (2008) who claimed that middle-aged journalists are announcing the demise of RP. He could assert it since 'they are observing the some of the currently ongoing changes in the accent' (Trudgill 2008).

Once the hypothesis of "changing RP" has been contrasted by different authors, it is customary to provide an overview of the ways in which this change is occurring. As Labov (1966) declared, 'change is from below'. When he proclaimed this statement, he based it on the idea that the normal pattern is one of changes spreading from lower sociolects to higher sociolects' (Labov 1966). Additionally, Trudgill (2008) supported his idea with the succeeding statement. 'Forms from lower-class speech spread and continue to spread into middle-class and then into upper-class speech'. (Trudgill 2008). The clear conclusion to draw from this is that if the phonological new tendencies presented in this project spread "from below" (Labov, 1966), they might be part of the future RP features. "We can suppose that just as change from below has been happening for the last several centuries, it will continue to happen" (Trudgill 2008). This allegation is motivated by the fact that it is conceivable to encounter many other traits of RP which used to belong to lower-class southern innovative linguistic tendencies and, later, spread upwards into RP. Thus, evidence of 
old features which are part of present RP can be provided. For instance, one of the features coming from low-class speech was the so-called phenomenon "intrusive-r". It was "condemned as vulgar at first" (Jespersen 1949), and it has characterised RP since the early $19^{\text {th }}$ century. Another phonological innovation in English was the insertion of the $/ \mathrm{N}$ / vowel. In fact, Wales does not possess it yet. At the beginning of the $20^{\text {th }}$ century, $/ \Lambda /$ can be regarded as one of the RP features.

Firstly, one of the new tendencies that has been presented in section 4.3 is "L vocalisation". Wells (1982) predicted that 'L vocalisation is beginning to seep into RP' and Gimson (2000) listed it as an innovation 'on the verge of RP'. Secondly, "T Glottaling" was another introduced feature as an innovation. Wells (1982) defined it as a trait which "has now become a feature of recent RP". Trudgill (2008) also gave his account when saying that 'we can assume that "T Glottaling" is probably a matter of time'. Thirdly, "Happy Tensing" is another phonological feature dealt with in this project. Regarding this phenomenon, Gimson (2000) refers to it as 'one of the changes which has already been well-established'. Therefore, "Happy Tensing" will no longer be a regional feature, though absence of "Happy Tensing will be". (Trudgill 2000).

\section{References}

GıMson, A (2000) Gimson's Pronunciation of English. Publicaciones en London, Edward Arnold.

JesPeRsen, O (1949). A Modern English Grammar On Historical Principles. Publicacions en Copenhagen, Munksgaard.

JOHnSON, W I D. BRITAIN (2007): L-Vocalisation as a Natural Phenomenon: Explorations in Sociophonology, Publicacions de Language Sciences.

KeSWILL, P (2000) Dialect Levelling And Received Pronunciation, Publicacions Online Web. 24 Abril.

LABOV, W (1966) The Social Stratification of English In New York City. Publicacions en Washington, Center for Applied Linguistics.

TRUDGILL, P (2000) The Role of Drift In The Formation Of Native-Speaker Southern Hemisphere Englishes: Some New Zealand Evidence. Publicacions Diachronica.

Trudgill, P (2008). Dialectology. Publicacions en la Universitat de Cambridge, Cambridge.

TRUDGILL, P (2008) The Historical Sociolinguistics of Elite Accent Change: On Why RP is not disappearing, Publicacions Agder University, Kristiansand.

Wells, J (1982) Accents of English. Publicacions en la Universitat de Cambridge, Cambridge. 